\section{Tuberculosis hits back}

\section{Return of the White Plague: \\ Global Poverty and the 'New' \\ Tuberculosis}

edited by Matthew Gandy \& Alimudden

Zumla

Verso: 2003. 320 pp. \$35, £25, Can\$51

\section{A. Mitchison}

People tell me that tuberculosis has come back, to which I reply: "It never went away." In the 1970s it was thought that tuberculosis was no longer a threat, at least in Britain, and would soon be eradicated. That this view was mistaken is illustrated in this book by a series of essays describing major failures in control and the hotspots where these failures are leading to the emergence of drug-resistant strains.

The World Health Organization estimates that there is steady but slow progress towards better control of tuberculosis worldwide. This progress could be accelerated by the widespread adoption of the DOTS strategy, a five-prong policy comprising government commitment, diagnosis by sputum smears, short-course chemotherapy with supervision of drug-taking, regular drug supplies, and sufficient record-keeping to allow progress to be analysed. An increasing number of countries across the world are adopting this strategy.

In contrast to this guarded optimism, the descriptions of the hotspots in Return of the White Plague paint a frightening picture. Dormant tuberculosis infections are frequently reactivated by HIV infection with devastating results. AIDS kills a sizeable proportion of the population in sub-Saharan Africa, often with terminal tuberculosis. The spread of HIV in these countries has been accelerated by political blindness at the highest level. The exception is Uganda, which was quick to recognize the need to explain the origin of HIV infection and how preventive methods could be used and, as a result, has successfully controlled its spread. Recent agreements by pharmaceutical companies to provide generic anti-retroviral drugs have raised hopes, although it is uncertain whether these can be used effectively in the huge populations afflicted with HIV. An effective vaccine is still far in the future.

The chapter on the outbreak of drugresistant tuberculosis in New York is marred by the gloomy prognostication that better treatment would not be an effective control measure. In fact, the control policy of improving treatment with compulsory segregation of patients with resistant strains, carried out by Paula Fujiwara, who ran the Bureau of Tuberculosis Control in New York, has been highly effective, although at its

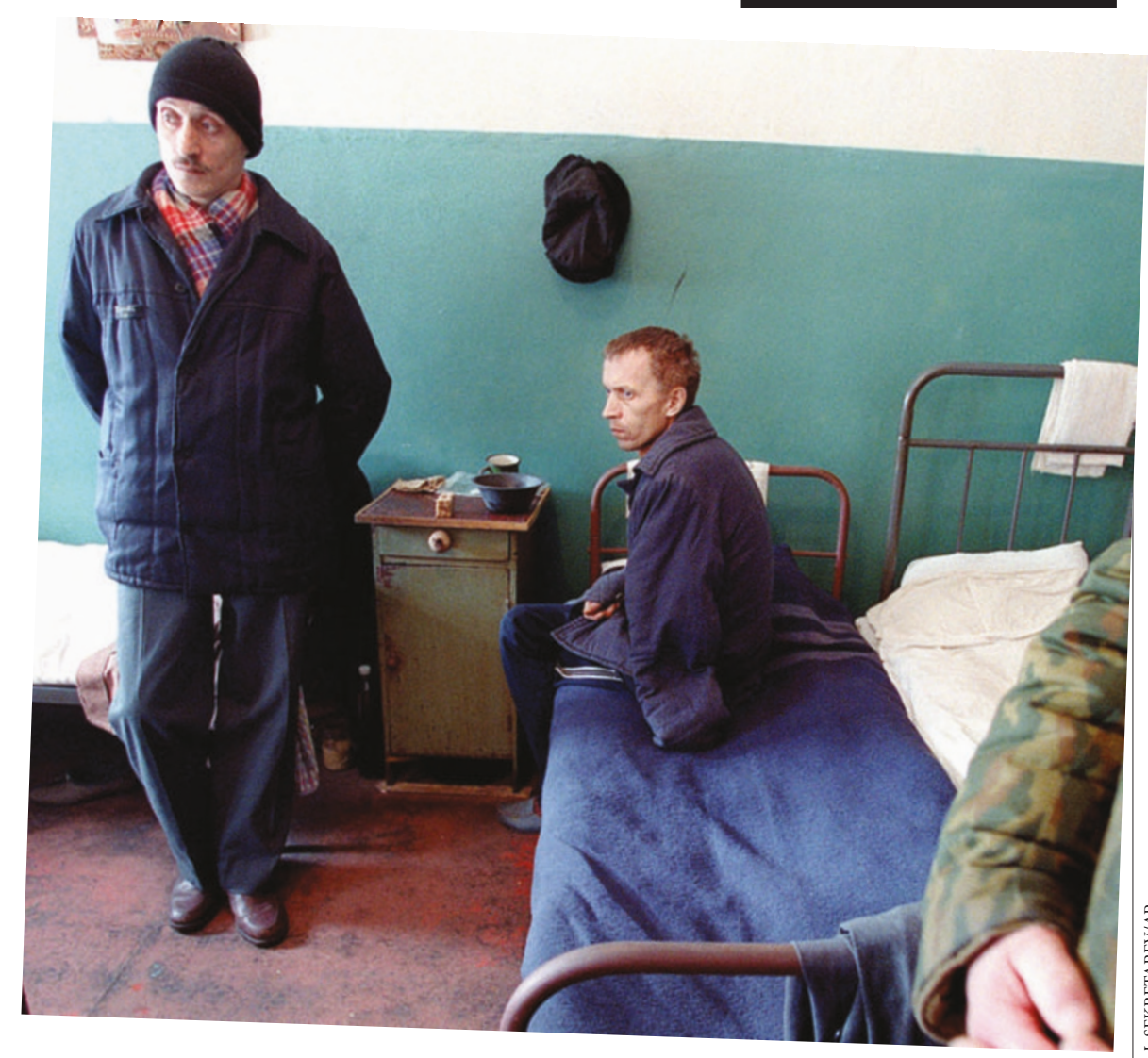

Locked up with a killer: drug-resistant tuberculosis is a widespread problem in Russia's prisons.

peak it cost $\$ 50$ million per year. The high incidence of tuberculosis in the poorest and most socially excluded populations in London cries out for a more determined and actively led control programme like that carried out in New York.

There are also chapters on drug-resistant tuberculosis in Haiti, Peru and, most frighteningly, in the prisons of the former Soviet bloc. The main reason for the Soviet problem was the failure of the authorities there to make any contact with those developing the successful treatment of the disease between 1950 and 1980. No clinical trial of the treatment was ever carried out in the Soviet Union. This political isolation led to the use of inappropriate regimens of treatment with the result that drug resistance became widespread. These core chapters of the book make us reflect on the main causes of the resurgence of tuberculosis: HIV infection; migration, which spreads HIV as well as tuberculosis; a lack of proper scientific leadership in control policies; and finally, and perhaps most importantly, poverty.

Other chapters are of mixed value and concentrate too much on failure rather than on possible progress. There are also notable omissions. For example, the introductory description of the tuberculous lesions only describes part of the process. The haematogenous spread from the primary site of infection to the adult lesions is not described at all, yet this is key to understanding why HIV infection results in such a high rate of reactivation of tuberculosis and how the BCG vaccine works in preventing the spread. Similarly, the chapter on immigration obscures the evidence that immigrants initially carry with them the tuberculosis incidence rate in the country from which they came.

Finally, chapters on advocacy and action include a good, albeit long-winded, account of the importance of doctors understanding their patients. The chapter on the role of science in tuberculosis control makes no mention of issues such as the duration of antigen stimulation, which is key to the understanding of DNA vaccines, nor to the development of short-course chemotherapy, or of the need for new drugs to shorten treatment and the current emphasis on using genomics in drug design.

The chapter ends with the hope engendered by DNA vaccines. Yet the UK Medical Research Council (MRC) has failed to support work in this area, despite recommendations from its own review committee that a clinical unit be established. Since 1986, support for basic research into tuberculosis in Britain has declined steadily, and there is now only a fragmented unit working at the MRC's lab at Mill Hill near London. How can the MRC defend its failure to support research on an infection of such worldwide importance?

D. A. Mitchison is in the Department of Medical Microbiology, St George's Hospital Medical School, Cranmer Terrace, London SW17 ORE, UK. 